\title{
Leo3D - Uma aventura pelo mundo da óptica
}

\author{
André L. A. Di Salvo ${ }^{1,2}$, Adriane B. S. Serapião ${ }^{3}$ \\ ${ }^{1}$ Instituto Federal de Educação, Ciência e Tecnologia do Sul de Minas Gerais \\ Campus Inconfidentes - Inconfidentes - MG \\ ${ }^{2}$ Universidade Estadual Paulista (Unesp), Instituto de Biociências \\ Rio Claro - SP \\ ${ }^{3}$ Universidade Estadual Paulista (Unesp), Instituto de Geociências e Ciências Exatas \\ Rio Claro - SP \\ andre.amaral@ifsuldeminas.edu.br, adriane@rc.unesp.br
}

\begin{abstract}
This paper presents the first results of a pilot test using Leo3D, a digital educational game for teaching geometric optics. The test was conducted in three distinct stages, which included pre and post-test about the contents of the course, in addition to the use of the game in the classroom. The initial results are promising, since growth in all evaluated items was noticed.
\end{abstract}

Resumo. Este artigo apresenta os primeiros resultados de um teste piloto utilizando o Leo3D, um jogo educativo digital destinado ao ensino de óptica geométrica. $O$ teste foi conduzido em três etapas distintas, que englobaram pré e pós-teste sobre os conteúdos da disciplina, além da utilização do jogo em sala de aula. Os resultados iniciais mostram-se promissores, uma vez que foi notado um crescimento em todos os itens avaliados.

\section{Introdução}

A atual geração de estudantes comumente conhecida como Geração Z, cresceu imersa em um mundo de tecnologias e ferramentas digitais como jogos, mídias sociais e mundo virtuais. Toda essa interação proporciona impactos diretos na forma como eles se divertem, socializam e principalmente, estudam. Na área educacional, além dessas tecnologias serem mais amigáveis do que os tradicionais livros, elas proporcionam novos meios de interação e visualização de conteúdos. Neste contexto, os Jogos Educativos Digitais (JED) surgem como uma ferramenta capaz de aliar educação com entretenimento.

Diversos pesquisadores têm explorado o potencial dos jogos, entre eles, Dias [Dias 2015], que desenvolveu o DigesTower, um JED na área de saúde que busca estimular uma alimentação saudável e a prática de exercícios físicos, a fim de combater a obesidade infantil, e Otsuka et al. [Otsuka et al. 2015] que apresentaram o LabTecA, um jogo de simulação na área de química analítica. Esses dois jogos estão vinculados ao Laboratório de Objetos de Aprendizagem (LOA) da Universidade Federal de São Carlos.

Outro laboratório que tem apresentado soluções nessa área é o Laboratório de Multimídia Interativa do IFSUDESTE/MG - Campus Rio Pomba (LAMIF). Entre os diversos projetos desenvolvidos, destacam-se o Kinble, que é voltado a preparação de alunos para o vestibular [Machado et al. 2011a], e o Frigote, destinado ao ensino do manejo de aves para alunos de cursos técnicos e superiores [Machado et al. 2011b]. 
VI Congresso Brasileiro de Informática na Educação (CBIE 2017)

Anais dos Workshops do VI Congresso Brasileiro de Informática na Educação (WCBIE 2017)

Além dos JED, jogos de cartas e tabuleiros têm sido utilizados no processo de ensino/aprendizagem. Dentro dessa iniciativa, Carlos et al. [Carlos et al. 2014] apresentaram uma proposta de jogo de cartas, painéis e marcadores voltados ao ensino de química, e Pereira [Pereira 2008] apresentou dois jogos de tabuleiro destinados ao ensino de física. São eles: i) Conhecendo a Física; ii) Ludoestática.

Frente ao crescimento do uso de jogos (digitais ou não) como estratégia de ensino, este trabalho tem como objetivo apresentar os primeiros resultados de um teste piloto do Laboratório de Ensino de Óptica 3D (Leo3D) com alunos do ensino médio.

\section{Leo3D}

O Leo3D é um JED em terceira pessoa voltado ao ensino de óptica geométrica que possui laboratórios de simulação e fases jogáveis. Os laboratórios de simulação possibilitam ao aluno enxergar de forma lúdica os conceitos de óptica. As fases jogáveis colocam em prática os conteúdos vistos nos laboratórios por meio de problemas e desafios que devem ser resolvidos dentro de um tempo pré-determinado. O jogo se passa nos dias atuais e mistura elementos da mitologia grega com astronomia. Hades, Deus do Mundo Subterrâneo, captura Hélios, Deus do Sol, após o alinhamento planetário ocorrido no ano de 2016. Com Hélios capturado, o Sol perde sua capacidade de iluminar e fornecer calor para a Terra. Para salvar o planeta, o jogador deve coletar esferas de energia que irão manter a Terra aquecida enquanto Hélios não é libertado.

Na versão Alpha 1.0, o Leo3D possui 11 laboratórios de simulação e duas fases jogáveis. Uma versão Alpha é uma etapa do processo no qual o motor do jogo e a interface estão prontas e o jogo pode ser jogado do início ao fim [Novak 2011]. A Figura 1 apresenta o laboratório de espelhos planos e um dos desafios da segunda fase do jogo.
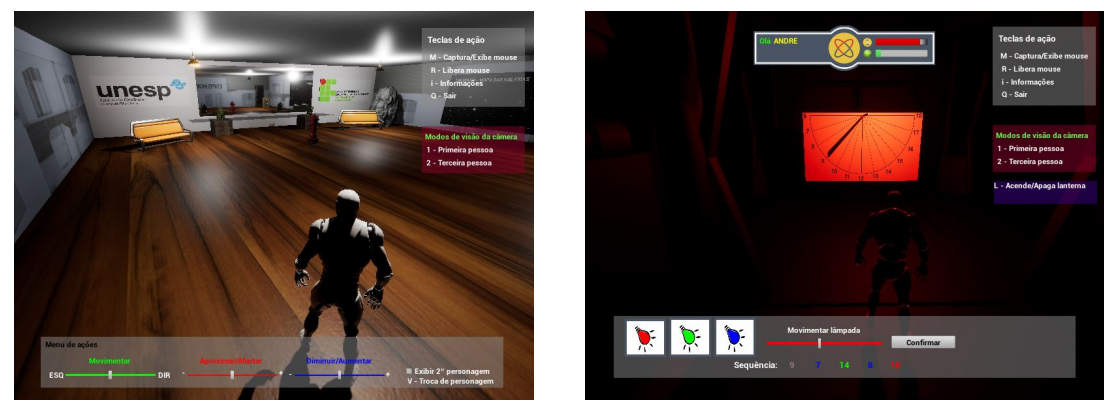

Figura 1. Leo3D - Laboratório e Fase

\section{Metodologia}

O Leo3D - Alpha 1.0 - foi testado e avaliado por meio de um teste piloto conduzido com alunos do $3^{\circ}$ ano do ensino médio. O processo foi dividido em três etapas distintas: i) pré-teste; ii) utilização do Leo3D; iii) pós-teste. Todas as etapas foram acompanhadas por um professor de física e por um professor da área de informática.

A utilização do pré-teste teve como objetivo avaliar os conhecimentos pré-adquiridos sobre óptica. Como este conteúdo é abordado no $2^{\circ}$ ano do ensino médio e os alunos já estavam no $3^{\circ}$ ano do ensino médio, esta etapa foi fundamental para avaliar a real efetividade da ferramenta. O pós-teste foi aplicado ao final do experimento, após a ferramenta 
VI Congresso Brasileiro de Informática na Educação (CBIE 2017)

Anais dos Workshops do VI Congresso Brasileiro de Informática na Educação (WCBIE 2017)

ter sido apresentada aos alunos. O pré e o pós-teste continham 11 questões de múltipla escolha e uma questão aberta. As questões presentes nos dois testes foram extraídas do livro didático adotado no Programa Nacional do Livro Didático 2015, 2016 e 2017 [Máximo and Alvarenga 2014], do questionário denominado Light and Optics Conceptual Evaluation (LOCE), que pertence ao projeto Active Learning in Optics and Photonics (ALOP) apresentado na World Conference on Physics and Sustainable Development (2005) [Alarcon et al. 2010] e do instrumento de avaliação proposto por Harres que avalia concepções alternativas sobre o conteúdo de óptica [Harres 1993]. Para garantir a paridade do grau de dificuldade, o mesmo questionário foi utilizado tanto no pré-teste quanto no pós-teste.

\section{Resultados}

Participaram da pesquisa 20 alunos devidamente matriculados em uma escola da rede federal de ensino. A Tabela 1 apresenta os resultados das questões de múltipla escolha do pré-teste e pós-teste. Ao analisar os itens menor e maior nota, observa-se um ganho de 1,00 ponto entre o pós-teste e o pré-teste. A média da turma apresentou um ganho expressivo da ordem de $38 \%$ (5,05 para 6,95 pontos). Outro item que se destaca é o número de alunos acima da média. Enquanto no pré-teste apenas 9 (nove) alunos alcançaram a média da prova, que correspondem a $45 \%$ da amostragem, no pós-teste esse número passou para 16 (dezesseis), ou seja, um crescimento no rendimento da turma de $78 \%$.

Tabela 1. resultados do pré e pós-teste

\begin{tabular}{|l|c|c|}
\hline & Pré-teste & Pós-teste \\
\hline Média da turma & 5,05 & 6,95 \\
\hline Maior nota & 8,00 & 9,00 \\
\hline Menor nota & 1,00 & 2,00 \\
\hline Alunos acima da média & 9 & 16 \\
\hline
\end{tabular}

Outra análise realizada refere-se ao índice de acertos das questões presentes no pré e pós-teste. A Figura 2 apresenta um gráfico com este índice.

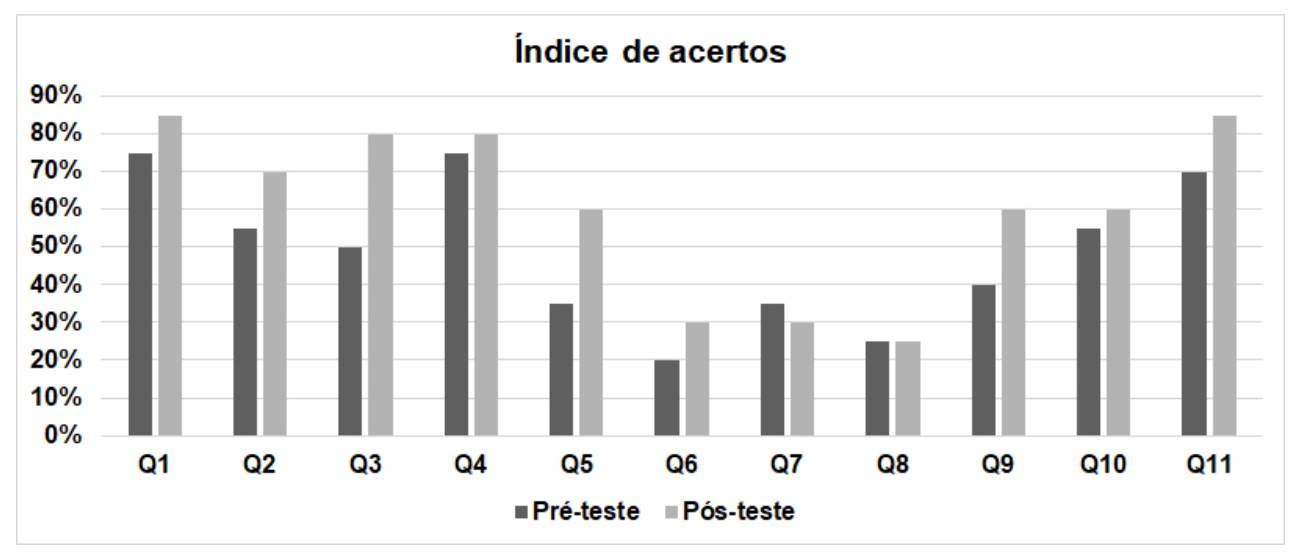

Figura 2. Índice de acerto das questões

Ao analisar o gráfico é possível perceber que a maioria das questões obtiveram um maior número de acertos no pós-teste em relação ao pré-teste. A questão $\mathrm{n}^{\circ} 8$ não 
apresentou diferença nos dois testes e a questão $\mathrm{n}^{\circ} 7$, um decréscimo de $5 \%$ no número de acertos nos pós-teste em relação ao pré-teste. Esta questão especificamente refere-se à altura de um objeto refletido em espelhos planos. Após esse resultado, uma análise mais criteriosa do texto e das alternativas da questão está sendo realizada para aferir se eles contribuíram para essa queda no número de acertos, tendo em vista que o conteúdo da ferramenta já foi aferido por professores da área de física e não foram encontrados erros na apresentação e abordagem do mesmo. A análise da questão aberta não apresentou ganhos entre os dois testes, com aproximadamente $60 \%$ dos alunos acertando a questão.

\section{Conclusão}

Com base neste primeiro teste piloto realizado com uma turma de alunos matriculados no $3^{\circ}$ ano do ensino médio, observa-se o potencial do Leo3D na mediação do processo ensino/aprendizagem dos conteúdos de óptica geométrica. O ganho de quase $80 \%$ no número de alunos que ficaram acima da média ( 9 para 16) mostra como os JED podem contribuir para uma melhor compreensão dos conteúdos, principalmente na área de Física, onde a maioria do material didático concentra-se em teorias e aplicações de equações, algo inexistente no Leo3D devido ao seu caráter lúdico em que foi pensado.

A continuação deste trabalho envolve o uso do Leo3D em turmas do $2^{\circ}$ ano do ensino médio. Desta forma, a real efetividade da ferramenta será avaliada em turmas que não tiveram acesso ainda ao conteúdo de óptica geométrica e que todas as concepções dos alunos sobre o assunto amparam-se em observações do dia-a-dia, ou seja, concepções alternativas de óptica geométrica. Para esta próxima etapa os participantes serão divididos em grupos controle e experimental, procedimento este não realizado neste estudo devido ao conteúdo já ter sido abordado em anos anteriores.

\section{Referências}

Alarcon, M., Lakhdar, Z. B., Culaba, I., Lahmar, S., Lakshminarayanan, V., Mazzolini, A. P., Maquiling, J., and Niemela, J. (2010). Active learning in optics and photonics (alop): a model for teacher training and professional development. In SPIE Optical Engineering + Applications, pages 778303-778303. International Society for Optics and Photonics.

Carlos, E. A., Sousa, F. A., Silva, R. G. T., Correia, D., Funayama, J. C., and Fassbinder, A. G. O. (2014). Elemento químico: Quantas evidências! um jogo como recurso didático para o ensino de química. In XXVIII Encontro Regional da Sociedade Brasileira de Química, Poços de Caldas.

Dias, J. D. (2015). Desenvolvimento de serious game para auxílio ao enfrentamento da obesidade infantil. PhD thesis, Universidade Federal de São Carlos.

Harres, J. B. S. (1993). Um teste para detectar concepções alternativas sobre tópicos introdutórios de ótica geométrica. Caderno Brasileiro de Ensino de Física, 10(3):220-234.

Machado, A. F., Cazetta, P. P., dos Santos, P. C., Figueiredo, A. M. O., Sant'ana, L. d. S., Junior, N. A. d. S., Sebastião de Freitas, E. D., and Clua, E. (2011a). Uma proposta de jogo educacional 3d com questões didáticas. In Brazilian Symposium on Computers in Education (Simpósio Brasileiro de Informática na Educação-SBIE), volume 1.

Machado, A. F. V., BATISTA, I. A., SANTIAGO, M. C., SANTOS, U. O., PADOVANI, R. R., SILVA, S. L. M., and CLUA, E. W. (2011b). Frigote: Uma proposta de ferramenta para apoiar o 
VI Congresso Brasileiro de Informática na Educação (CBIE 2017)

Anais dos Workshops do VI Congresso Brasileiro de Informática na Educação (WCBIE 2017)

ensino de avicultura. In Brazilian Symposium on Computers in Education (Simpósio Brasileiro de Informática na Educação-SBIE).

Máximo, A. and Alvarenga, B. (2014). Física: contexto e aplicações. Editora Scipione.

Novak, J. (2011). Game development essentials: an introduction. Cengage Learning.

Otsuka, J. L., Bordini, R. A., Beder, D. M., de Camargo, A. E. R., Menato, T., and Borges, M. T. M. R. (2015). Labteca: Experiência lúdica em umlaboratório 3d de química. Novas Tecnologias na Educação, 13(2).

Pereira, R. F. (2008). Desenvolvendo jogos educativos para o ensino de Física: um material didático alternativo de apoio ao binômio ensino-aprendizagem. 2008. $\mathrm{PhD}$ thesis, Dissertação (Mestrado). Mestrado em Educação para a Ciência e o Ensino de Matemática, Universidade Estadual de Maringá. 